\title{
Analysis of sustainability presence in Spanish Higher Education
}

\author{
Fermín Sánchez-Carracedo, Bárbara Sureda \\ University Research Institute for Sustainability Science and Technology (IS.UPC), Universitat Politècnica \\ de Catalunya (UPC-BarcelonaTech), Barcelona, Spain, and \\ Francisco Manuel Moreno-Pino \\ Teaching department, Facultad de Ciencias de la Educación, University of Cádiz, Cádiz, Spain
}

\section{DOI 10.1108/IJSHE-10-2019-0321}

Published at International Journal of Sustainability in Higher Education, Vol 21, No 2, pp. 393-412, 2020

Received: date: 31-Oct-2019; Revised: 26-Dec-2019; Accepted: 9-Jan-2020

Citation

Sánchez-Carracedo, F., Sureda Carbonell, B. and Moreno-Pino, F. (2020), "Analysis of sustainability presence in Spanish higher education", International Journal of Sustainability in Higher Education, Vol. 21 No. 2, pp. 393-412. https://doi.org/10.1108/IJSHE-10-2019-0321

\section{Deposit licences}

This Author Accepted Manuscript (AAM) is deposited under the Creative Commons Attribution Non-commercial International Licence 4.0 (CC BY-NC 4.0). Any reuse is allowed in accordance with the terms outlined by the licence. To reuse the AAM for commercial purposes, permission should be sought by contacting permissions@emeraldinsight.com.

For the sake of clarity, commercial usage would be considered as, but not limited to:

o $\quad$ Copying or downloading AAMs for further distribution for a fee;

- Any use of the AAM in conjunction with advertising;

o $\quad$ Any use of the AAM by for promotional purposes by for-profit organisations;

o Any use that would confer monetary reward, commercial gain or commercial exploitation.

\section{Abstract}

\section{Purpose}

This paper analyzes the presence of sustainability in sixteen Spanish Higher Education curricula in the fields of Education and Engineering.

\section{Design/Methodology/Approach}

The methodology employs two instruments: the Sustainability Map and the Sustainability Presence Map. These instruments enable the following: to analyze the number of subjects that develop sustainability and the sustainability presence level in each curriculum; to identify at what domain levels of the learning taxonomy sustainability is most developed; and to analyze whether a correlation exists between the sustainability presence and the number of subjects that develop sustainability in each curriculum. 


\section{Findings}

A wide variety of subjects develop sustainability in a given degree, depending on the university. The presence of sustainability is more homogeneous in education degrees than in engineering degrees. Education degrees have a greater presence of sustainability in the lower domain levels of the taxonomy, while in engineering degrees the lower levels of the taxonomy have a lower presence of sustainability than the higher levels. Finally, a correlation appears to exist between the number of subjects that develop sustainability in the curriculum and the sustainability presence. However, engineering degrees seem to need fewer subjects than education degrees to achieve the same degree of sustainability presence.

\section{Originality/Value}

This paper proposes a methodology to measure sustainability presence that can be applicable to the curricula of a Higher Education degree if the corresponding Sustainability Map is available. To our knowledge, this is the largest study yet conducted to analyze the presence of sustainability in different Higher Education curricula.

\section{Keywords}

Presence of sustainability, sustainability competencies, Sustainability Map, Sustainability Presence Map, Spanish Higher Education degrees, Spanish engineering degrees.

\section{Introduction}

Throughout this century, humanity will be faced with overriding problems (social imbalances, climate change, water availability, etc.). To successfully overcome these challenges, the participation of society and governments will be required, both in actions and in policies that help ensure a healthy environment and a socially just and economically prosperous future for all (Fien and Maclean, 2000). To this end, it is necessary to understand the interactions between nature and society. This is one of the objectives of sustainability science (Kates et al., 2001), which is vital if society is to address the challenges of global and local sustainability effectively (UNESCO, 2017-1).

In 2015 the United Nations approved the 2030 agenda, which contains a set of 17 objectives called Sustainable Development Goals (UN, 2015) that must be achieved in 2030. These objectives are intended to protect the planet and ensure peace and prosperity for all its inhabitants. One of the key elements in the move towards sustainability is education, as recognized by UNESCO (2017-2). Some authors believe that education is a synergistic factor for the objectives of the 2030 Agenda to be achieved (Giangrande et al., 2019; Hallinger and Chatpinyakoop, 2019). Indeed, Goal 4.7 of Sustainable Development Goal 4 addresses Education for Sustainable Development (ESD), and recognizes it as an essential factor for the achievement of sustainability. In this work, the terms sustainability and ESD will be used interchangeably as synonyms, although in some contexts small differences can be found between both concepts.

Education is essential for training agents of change and the transformation of society (Mulder et al., 2012). Educators face a great responsibility: to help society move towards sustainable development (Mortensen, 2000). In this sense, higher education plays a fundamental role in contributing to the training of these agents (Stephens and Graham, 2010).

Some proposals have tried to evaluate Sustainable Development (SD) in higher education. The AISHE (Assessment Instrument for Sustainability in Higher Education), developed by the DHO (Dutch Foundation for Sustainable Higher Education), evaluates SD in five modules: (1) Identity, (2) Education, (3) Research, (4) Operations, and (5) Societal Outreach, by using a set of indicators. AISHE can be applied freely by any university (see http://www.eauc.org.uk/theplatform/aishe for more information). Also noteworthy is the proposal of Times Higher Education, which evaluates and classifies universities according to their performance in achieving the United Nations Sustainable Development Goals. The evaluation is carried out in three areas: research, outreach, and stewardship. The university that leads the ranking is the University 
of Auckland in New Zealand, followed by the McMaster University of Canada (see https://www.timeshighereducation.com/rankings/impact/2019/ for more information). Other interesting work, published by the International Association of Universities (IAU, 2017), analyses the role of higher education in fostering SD using a global survey answered by 120 higher education institutions around the world. The report concludes that, although SD is being integrated within higher education institutions, including at strategic level, there still remains room for improvement.

Thus, the necessity of including sustainability in the curricula of higher education degrees is clear (Sonetti et al., 2019). An important aspect to consider in order to succeed in this goal is to engage the commitment of those who should lead the process. This commitment is essential for the move towards a more sustainable world (Ralph and Stubbs, 2014). It is also important to design a sustainability integration process for the curriculum that can be evaluated so that, if necessary, it can be modified by using objective criteria (Khoen and Uitto, 2014). Some authors have therefore focused their research on the design of basic principles of ESD that should be integrated into the curriculum (Tassone et al., 2018). Other authors have analyzed how ES is being introduced in Higher Education curricula around the world by means of different strategies. Alejandro-Cruz et al. (2019) analyzed how the concept of sustainability is being incorporated into global research of higher education by using different scientometric reviews of global research between 1991 and 2018. Based on the review of 6724 articles and conference proceedings, they built up a picture of the main institutions that have significantly contributed to the topic of sustainability in higher education, and found that $40.58 \%$ of the records originate in institutions from the United States, China, United Kingdom, and Australia.

Another factor to be taken into account is the training of university teachers (Svanström et al., 2012). Some authors have investigated this topic and have identified the main ideas that influence teachers in their teaching practice. This is a necessary measure to enable the definition of the training process required to ensure that teachers are capable of including ESD as effectively as possible in the subjects they teach (Shephard and Furnari, 2013). Other authors have focused their research on analyzing how to transfer knowledge in sustainability so that this efficacy can be achieved (Poza-Vilches et al., 2019).

Different approaches have been adopted to incorporate sustainability into a curriculum. On the one hand, learning outcomes related to sustainability are included in curriculum subjects, whether compulsory or elective (Sánchez Carracedo et al., 2018-1). On the other hand, specific subjects on sustainability are included in the curricula (Ceulemans and De Prins, 2010). A third approach consists of applying sustainability criteria in the final degree thesis (Chiong et al., 2017; Sánchez Carracedo et al., 2018-2).

These different ways of incorporating ESD into the curriculum involve different degrees of sustainability development and learning. On the basis of analysis by learning outcomes, some authors have investigated the essential conditions required for ESD to be included in a curriculum (Hill and Wang, 2018), while others have evaluated the result of incorporating sustainability-related learning outcomes in different courses and the performance achieved by students (Jarchow et al., 2019). Based on a scientific literature review on sustainability, Berchin et al. (2017) identified the recurrent actions for sustainability carried out in some Higher-Education Institutions, and focused these actions in a case study in Brazil.

Previous works have proposed the use of competency maps to distribute learning outcomes among the different subjects of the curriculum (Sánchez-Carracedo et al., 2018-1), and apply this idea to build a sustainability map. A sustainability map contains the sustainability-related learning outcomes that graduates are expected to have acquired on completion of their studies. These learning outcomes are distributed across several domain levels, depending on the learning taxonomy used. The curriculum must define a set of subjects (compulsory and/or elective) that constitute the "sustainability itinerary", and the learning outcomes of the sustainability map are distributed among the subjects of the sustainability itinerary. The sustainability map helps students to acquire a holistic view of the concept of sustainability by relating it to the technical (specific) competencies of their degree. It is essential for students to have this holistic vision if they are to be capable of addressing different approaches to sustainability when exercising their profession (Sinakou et al., 2018). Other authors, such as Casarejos et al. (2017), propose a conceptual framework for modeling the Higher-Education-Institutions' organizational environment. This work puts forward a set of strategic sustainability actions to drive movements toward sustainability, and also an assessment scheme. This scheme contains four indices to measure (1) the degree of commitment, (2) parity, (3) difficulty and (4) institutional performance throughout the implementation process of the actions proposed. 
In order to arrive at a correct definition of the sustainability-related learning outcomes that must be developed in a curriculum, it is first necessary to clarify the competencies related to sustainability that should be considered. Some authors have identified the following competencies related to sustainability: systems-thinking, anticipatory, normative, and strategic and interpersonal competency (Wiek et al., 2011; Wiek et al., 2015). Other authors have studied how these competencies should be adapted to the real situation of different countries, and concluded that there is no single model (Demssie et al., 2019).

Spanish universities have started to introduce ESD in the curricula using the document "Guidelines for the Introduction of Sustainability in the Curriculum" (CRUE, 2012). These guidelines were drawn up after an exhaustive study of the different proposals on sustainability competencies found in the literature, and recommend the inclusion of four competencies related to sustainability in the curricula of all Spanish university degrees (although the document provides no precise instructions on how this integration should be carried out in each curriculum):

- C1: Critical contextualization of knowledge by establishing interrelations with social, economic, environmental, local and/or global problems.

- C2: Sustainable use of resources and prevention of negative impacts on the natural and social environment.

- C3: Participation in community processes that promote sustainability.

- C4: Application of ethical principles related to the values of sustainability in personal and professional behavior.

On the basis of these four competencies, the EDINSOST project diagnoses the degree of sustainability in the Spanish Higher Education at three levels of incidence:

- Analysis of the presence of sustainability in the curricula,

- Analysis of teacher sustainability competencies, and

- Analysis of student sustainability competencies.

The tool used in the EDINSOST project is the sustainability map (Sánchez-Carracedo et al., 2018-1; Sánchez-Carracedo et al., 2018-3), which consists of a matrix containing learning outcomes. The rows of the matrix contain the four competencies (C1-C4) identified in the document mentioned above (CRUE, 2012). The columns enable learning outcomes to be classified into three domain levels using as taxonomy a simplified version of the Miller Pyramid (Miller, 1990). In this taxonomy, the two top domain levels (Demonstrate and Do) are unified into a single level. The taxonomy used take the following domain levels into account:

- Know

- Know how

- $\quad$ Demonstrate + Do

This paper focuses on the analysis of the first level of incidence of the EDINSOST project: the presence of sustainability in the curricula of the Spanish higher education degrees. The analysis was carried out on a set of degrees belonging to two areas of knowledge: Education and Engineering (Segalàs et al., 2018). The analysis of the other two levels of impact will be addressed in future papers.

\section{Research Questions and methodology}

\subsection{Objectives and research questions}

The general objective of this paper is to analyze the presence of sustainability in a set of Spanish higher education degrees in the fields of Education and Engineering, and compare the results according to the area of knowledge, degree, and domain level of the taxonomy. Four specific objectives are proposed:

- Analyze the number of subjects that develop sustainability in each Degree. 
- Analyze the presence of sustainability competencies defined by the CRUE ${ }^{1}$ (CRUE, 2012) in the curriculum of each Degree.

- For each of the sustainability competencies, identify which domain levels are developed to a greater or lesser extent in each Degree.

- Analyze if there is a correlation between the number of subjects that develop sustainability in each Degree and the presence of the four sustainability competencies.

The research questions drawn up are as follows:

1. In how many subjects is sustainability present in the curricula of each Degree? Is the number of subjects that develop sustainability in the different degrees homogeneous? And in the different universities? Are there significant differences between education and engineering degrees?

2. To what extent are sustainability competencies present in the curricula of each Degree? Is there a homogeneous treatment in the development of sustainability competencies between the different degrees? And between the different universities? Do significant differences exist between education and engineering degrees?

3. What presence do the sustainability competencies have in each domain level of the taxonomy? Are there significant differences between education and engineering degrees?

4. Is there a correlation between the number of subjects that develop sustainability in each curriculum and the presence of sustainability? If so, are there significant differences in the correlation found between education and engineering degrees?

\subsection{Sample}

The sample of degrees analyzed in this work is a subset of the degrees studied by the EDINSOST project. For education degrees, sixteen curricula from seven universities have been analyzed: Autonomous University of Madrid (UAM), University of Cádiz (UCA), University of Córdoba (UCO), International University of Catalonia (UIC), University of Seville (US), University of Salamanca (USAL) and Camilo José Cela University (UCJC). The curricula analyzed belong to four different degrees:

- Bachelor Degree in Early Childhood Education (BDECE) at UAM, UCA, UCO, UIC, US and USAL;

- Bachelor Degree in Primary Education (BDPE) at UAM, UCA, UCO, UIC, US, USAL and UCJC;

- Bachelor Degree in Pedagogy (BDP) at US and USAL;

- Bachelor Degree in Social Education (BDSE) at USAL;

For engineering degrees, ten curricula from three universities have been analyzed: University of Córdoba (UCO), Universitat Politècnica de Catalunya - BarcelonaTech (UPC) and Universidad Politécnica de Madrid (UPM). These curricula belong to six different degrees:

- Bachelor Degree in Electrical Engineering (BDEE) at UCO and UPC;

- Bachelor Degree in Informatics Engineering (BDIE) at UCO, UPC, and UPM;

- Bachelor Degree in Mechanical Engineering (BDME) at UCO and UPC;

- Bachelor Degree in Design Engineering (BDDE) at UPC;

- Bachelor Degree in Chemical Engineering (BDCHE) at UPM;

- Bachelor Degree in Industrial-Technologies Engineering (BDITE) at UPM.

The authors consider that the size and representativeness of the sample analyzed do not allow the results obtained to be generalized, but give relevant information on the degree of development of sustainability competencies in the Spanish university system in the education and engineering degrees.

\subsection{Instruments}

The methodology employed in this work makes use of two instruments to define the degree of presence of sustainability in the curriculum: the Sustainability Map of the EDINSOST project and the Sustainability Presence Map.

\footnotetext{
${ }^{1}$ CRUE refers to the Conference of Presidents of Spanish Universities
} 
- The definition of the Sustainability Map has been one of the objectives of the EDINSOST project (Segalàs et al., 2018; Tejedor et al., 2019). EDINSOST defines a common Sustainability Map for all engineering degrees (Engineering Sustainability Map, Sánchez-Carracedo et al., 2018-3) and another for all education degrees (Education Sustainability Map, Sánchez-Carracedo et al., 20191). Both maps consist of a matrix like the one described at the end of the Introduction, and contain learning outcomes related to engineering or education degrees. The fields of Education and Engineering are very different in Higher Education, and designing a single Sustainability Map for both has not been possible. Although sustainability is a transversal competency, sustainability competencies must be integrated into the curriculum so that graduates incorporate them into their profession. Therefore, the learning outcomes of both maps are quite different, despite the fact that both start from the same four sustainability competencies, and both use the same learning taxonomy. The domain levels of the simplified Miller Pyramid (L1: Know, L2: Know How, and L3: Demonstrate + Do) allow sequencing the acquisition of learning outcomes of each sustainability competency towards increasingly mature and complete states.

- The Sustainability Presence Map of a curriculum is a Sustainability Map in which the matrix cells contain a number greater than or equal to zero, rather than learning outcomes. This number expresses the number of subjects that develop some of the learning outcomes of the cell in the Sustainability Map. If a cell in the Sustainability Presence Map contains a number greater than zero, it is assumed that the competency related to the cell is developed in the curriculum at the domain level in which the cell is located (regardless of the number of subjects and hours dedicated to this development). The presence of each sustainability competency depends on the number of domain levels in which the competency is developed. Thus, if a competency is developed in the three domain levels, the presence of the competency will be $100 \%$, while if only one level is developed the presence will be 33\% (regardless of the number of subjects that develop it in each domain level and the number of learning outcomes that are developed in the curriculum).

The Sustainability Map is related to a Degree, while the Sustainability Presence Map is linked to a curriculum. Therefore, the 16 Education curricula will share the same Education Sustainability Map, but each of them will have its own Sustainability Presence Map (the same applies in the 10 engineering curricula). To build each Sustainability Presence Map, the learning guides of all the subjects of the curriculum have been thoroughly revised, linking the learning outcomes of the subjects with the learning outcomes of the Sustainability Map.

Table 1 presents the Sustainability Presence Maps of the education and engineering degrees used in this work. The top half of the table contains the Sustainability Presence Map of the education degrees, while the bottom half contains the Sustainability Presence Map the engineering degrees. The names of the analyzed curricula are shown in the column on the left. The following columns indicate the university in which the degree is taught (UNIV), the number of subjects that declare to develop sustainability in each curriculum $(\mathrm{N})$, and the presence of each of the 4 sustainability competencies (C1-C4). When a degree is taught in more than one university, the last row of the degree shows the average of the values found in all the curricula analyzed.

Table 1 Sustainability Presence Map of education and engineering degrees

\begin{tabular}{|c|c|c|c|c|c|c|}
\hline Degree & UNIV & $\mathbf{N}$ & C1 & $\mathbf{C 2}$ & $\mathbf{C 3}$ & C4 \\
\hline \multicolumn{7}{|c|}{ EDUCATION DEGREES } \\
\hline \multirow{7}{*}{ BDECE } & UAM & 8 & 1 & 1 & 1 & 1 \\
\hline & UCA & 26 & 1 & 1 & 1 & 1 \\
\hline & $\mathrm{UCO}$ & 36 & $5 / 6$ & $1 / 3$ & 1 & $3 / 6$ \\
\hline & UIC & 20 & 1 & 1 & 1 & 1 \\
\hline & US & 19 & $5 / 6$ & $1 / 3$ & $2 / 3$ & $4 / 6$ \\
\hline & USAL & 20 & $5 / 6$ & 0 & 0 & 1 \\
\hline & $\bar{x}$ & 21.50 & 0.92 & 0.61 & 0.78 & 0.86 \\
\hline \multirow{6}{*}{ BDPE } & UAM & 19 & 1 & 1 & 1 & 1 \\
\hline & UCA & 30 & 1 & 1 & 1 & 1 \\
\hline & UCJC & 11 & $5 / 6$ & $2 / 3$ & $1 / 3$ & 1 \\
\hline & UCO & 45 & $3 / 6$ & $1 / 3$ & 1 & $5 / 6$ \\
\hline & UIC & 19 & 1 & 1 & 1 & 1 \\
\hline & US & 9 & $1 / 6$ & 0 & $2 / 3$ & $2 / 6$ \\
\hline
\end{tabular}




\begin{tabular}{|c|c|c|c|c|c|c|}
\hline & USAL & 28 & 1 & $1 / 3$ & 0 & $4 / 6$ \\
\cline { 2 - 7 } & $\bar{x}$ & 23.00 & 0.79 & 0.62 & 0.71 & 0.83 \\
\hline \multirow{3}{*}{ BDP } & US & 11 & 1 & 1 & 1 & 1 \\
\cline { 2 - 7 } & USAL & 27 & $3 / 6$ & $2 / 3$ & 1 & $4 / 6$ \\
\cline { 2 - 7 } & $\bar{x}$ & 19.00 & 0.75 & 0.83 & 1.00 & 0.83 \\
\hline \multirow{3}{*}{ BDSE } & USAL & 27 & $5 / 6$ & $2 / 3$ & 1 & $5 / 6$ \\
\cline { 2 - 7 } & $\bar{x}$ & 27.00 & 0.83 & 0.67 & 1.00 & 0.83 \\
\hline
\end{tabular}

\section{ENGINEERING DEGREES}

\begin{tabular}{|c|c|c|c|c|c|c|}
\hline \multirow{3}{*}{ BDEE } & UCO & 3 & 0 & $1 / 12$ & 0 & 0 \\
\cline { 2 - 7 } & UPC & 10 & $2 / 3$ & $7 / 12$ & 0 & 1 \\
\cline { 2 - 7 } & $\bar{x}$ & 6.50 & 0.33 & 0.33 & 0.00 & 0.50 \\
\hline \multirow{3}{*}{ BDIE } & UCO & 36 & $1 / 3$ & 0 & 0 & $2 / 3$ \\
\cline { 2 - 7 } & UPC & 13 & $2 / 3$ & $11 / 12$ & 1 & 1 \\
\cline { 2 - 7 } & UPM & 11 & 1 & $7 / 12$ & $1 / 3$ & 1 \\
\cline { 2 - 7 } & $\bar{x}$ & 20.00 & 0.67 & 0.50 & 0.44 & 0.89 \\
\hline \multirow{3}{*}{ BDME } & UCO & 4 & 0 & $1 / 4$ & 0 & $1 / 3$ \\
\cline { 2 - 7 } & UPC & 3 & $1 / 2$ & $1 / 3$ & 0 & $2 / 3$ \\
\cline { 2 - 7 } & $\bar{x}$ & 3.50 & 0.25 & 0.29 & 0.00 & 0.50 \\
\hline \multirow{2}{*}{ BDDE } & UPC & 9 & 1 & $3 / 4$ & 1 & 1 \\
\cline { 2 - 7 } & $\bar{x}$ & 9.00 & 1.00 & 0.75 & 1.00 & 1.00 \\
\hline \multirow{2}{*}{ BDCHE } & UPM & 7 & $2 / 3$ & $11 / 12$ & 0 & 1 \\
\cline { 2 - 7 } & $\bar{x}$ & 7.00 & 0.67 & 0.92 & 0.00 & 1.00 \\
\hline \multirow{2}{*}{ BDITE } & UPM & 7 & $2 / 3$ & $11 / 12$ & 0 & 1 \\
\cline { 2 - 7 } & $\bar{x}$ & 7.00 & 0.67 & 0.92 & 0.00 & 1.00 \\
\hline
\end{tabular}

Some competencies are defined in the Sustainability Map in terms of more than one competency unit -see Sánchez-Carracedo et al. (2018-1) for details-. Specifically, competences C1 and C4 are defined by 2 competency units in the Education Sustainability Map. As each competency unit defines its learning outcomes in 3 domain levels (Know, Know how and Demonstrate + Do), competencies C1 and C4 distribute their learning outcomes in 6 cells, while competencies $\mathrm{C} 2$ and $\mathrm{C} 3$ distribute them in only 3 cells. Thus, for example, the presence of competency $\mathrm{C} 4$ for the BDECE of the UCO is $3 / 6$ because the subjects of the curriculum develop learning outcomes belonging to 3 of the 6 cells. This value is included in a circle in Table 1 to identify it clearly. The Education Sustainability Map can be found in Sánchez-Carracedo et al. (2019-1).

In the case of the Engineering Degrees, competency $\mathrm{C} 1$ has 2 competency units (therefore 6 cells contain learning outcomes) and competency $\mathrm{C} 2$ has 4 competency units (12 cells contain learning outcomes). The $\mathrm{C} 3$ and $\mathrm{C} 4$ competencies contain a single competency unit, and therefore their learning outcomes are distributed in 3 cells in each one. The Engineering Sustainability Map can be found in Sánchez-Carracedo et al. (2018-3).

The process for building the Sustainability Presence Maps of education and engineering degrees is detailed in Sánchez-Carracedo et al. (2019-1) for education degrees, and in Sánchez-Carracedo et al. (2019-2) for engineering degrees.

\subsection{Research design}

The design used in this research is quantitative, since for each curriculum of each university, the presence of each of the four competencies related to sustainability is calculated. The average is used to calculate the sustainability presence in the education degrees set and the engineering degrees set.

To calculate the sustainability presence in the Spanish university system, a weighted average is used, given that data are available from 16 Education curricula and 10 Engineering curricula. In this way, education degrees and engineering degrees are observed to have a $50 \%$ influence on the final result.

Finally, the temporality of the study and the analysis performed correspond to the data extracted from the 2018-2019 academic year. 


\section{Results and Discussion}

\subsection{Subjects that develop sustainability in curricula}

Figures 1(a) and 1(b) enable the first block of research questions to be answered: In how many subjects is sustainability present in the curricula of each Degree? Is the number of subjects that develop sustainability in the different degrees homogeneous? And in the different universities? Are there significant differences between education and engineering degrees?

Figure 1(a) shows the value of the average of subjects (axis y) in which sustainability is stated to have been developed, organized by areas of knowledge and degrees (axis x), and the standard deviation of the curricula of each degree. When a degree is taught in a single university (BDSE, BDDE, BDCHE, BDITE), the bar on the left indicates the number of subjects that develop sustainability in the degree. In this case, the standard deviation (right bar) is 0. If the degree is taught in several universities, the left bar shows the average number of subjects, and the right bar shows the standard deviation. The group of bars on the left corresponds to education degrees, while the group of bars in the center corresponds to engineering degrees. Finally, the group of bars on the right shows the weighted average of subjects and the standard deviation of the degrees according to their area of knowledge. 


\section{Average of subjects}

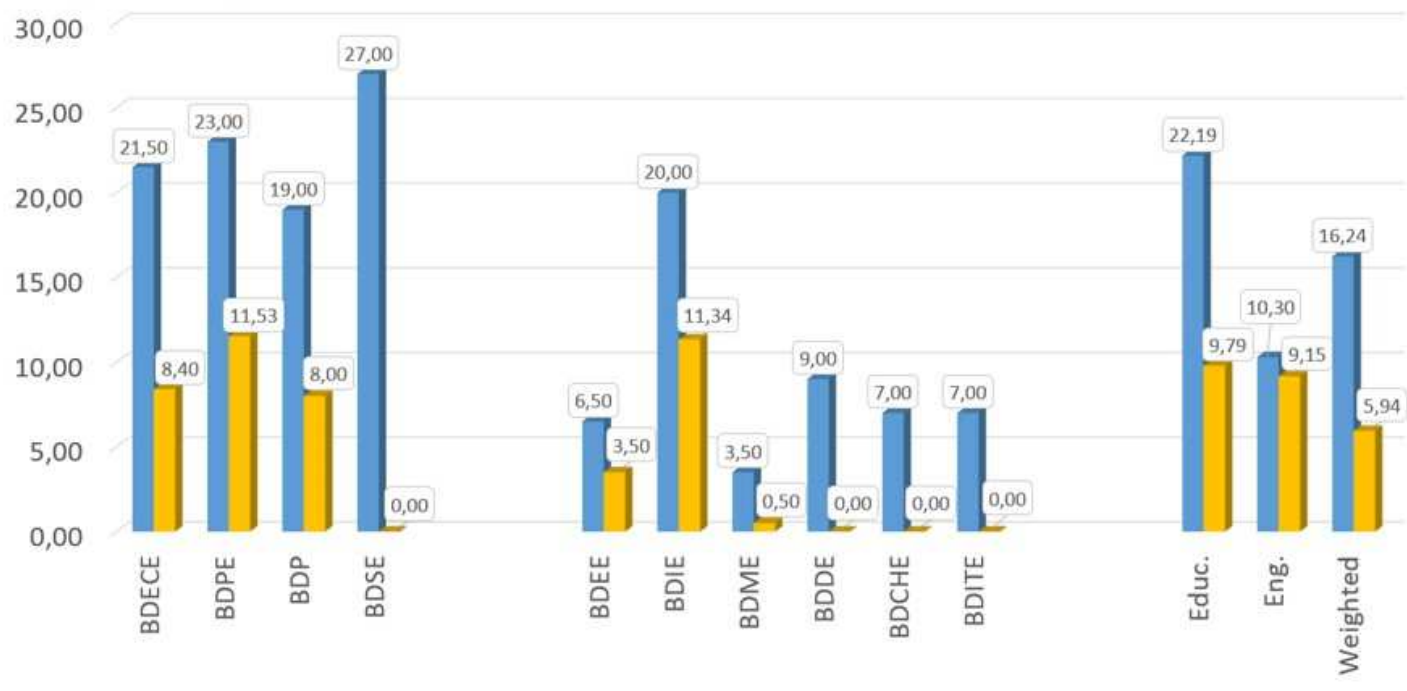

Education

Engineering

Average

\section{Average of subjects}

ESubjects = Deviation

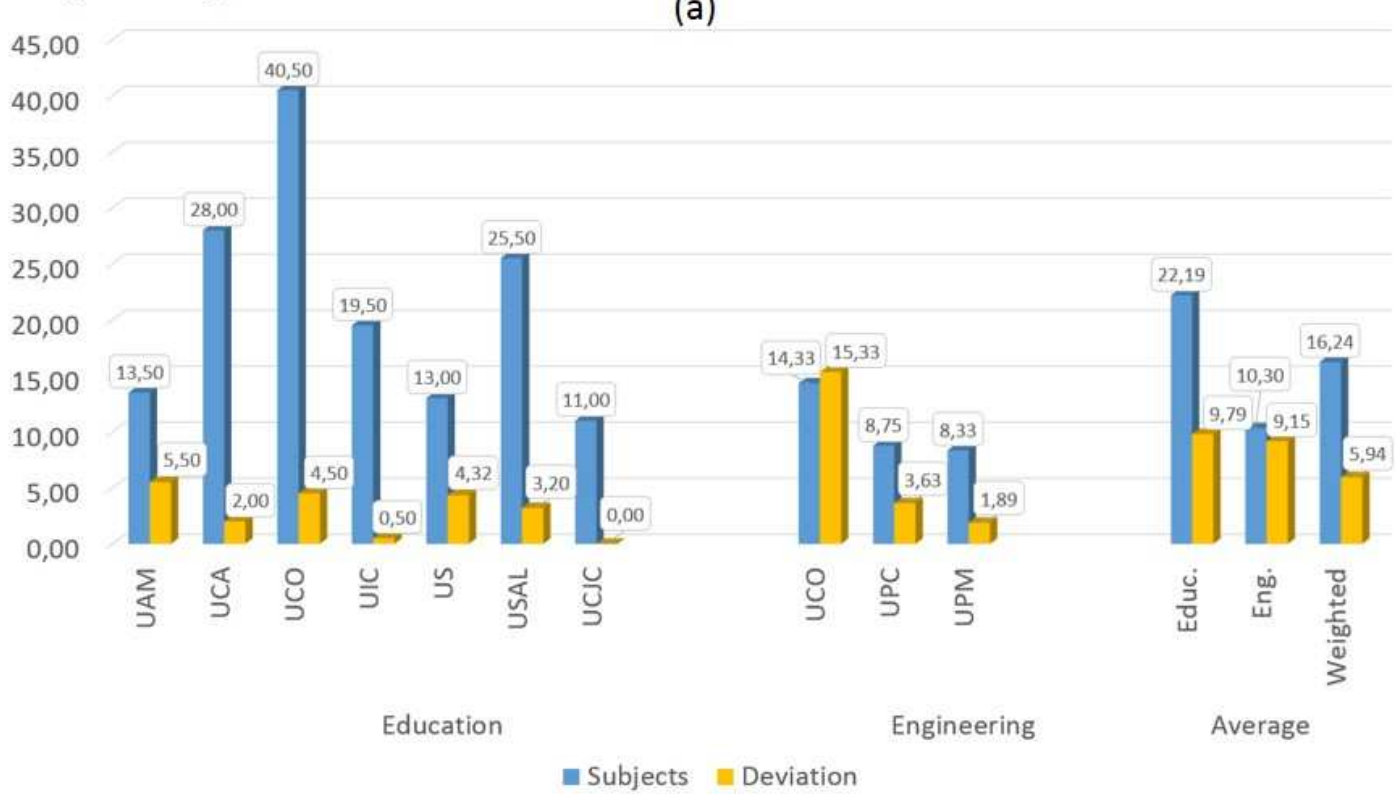

(b)

Fig 1 Average of subjects in which it is stated that sustainability is developed, and standard deviation, (a) organized by degrees and areas of knowledge, and (b) organized by universities.

The high values in the standard deviation shown in Figure 1(a) indicate that the total number of subjects in which it is stated that sustainability is developed in these degrees is very varied. For example, the value 11.53 in the standard deviation of the BDPE (Education), or the value 11.34 of the BDIE (Engineering), indicate that the number of subjects that develop sustainability in these degrees is not homogeneous, and depends to a great extent on the university that teaches the degree.

On the other hand, Figure 1(a) shows that, on average, education degrees develop sustainability in more than twice as many subjects as engineering degrees (22.2 vs. 10.3 subjects).

Figure 1(b) shows the same information as Figure 1(a), but organized by universities. The lower values in the standard deviation shown in Figure 1(b) indicate that the distribution of subjects is more homogeneous when analyzed by universities. However, the differences in the number of subjects that develop sustainability in each university is notable ( 40.5 in the UCO versus only 11 , on average, in the UCJC for 
education degrees). The data in figures 1(a) and 1(b) suggest that there appears to be no clear "strategy" for implementing sustainability between the different universities (very different average number of subjects ), but they are compatible with the existence of such a strategy within each university (low deviation type), with the exception of the UCO for Engineering (the only university where the standard deviation exceeds the average). This case is an outlier, as will be analyzed later. On the other hand, there appears to be no strategy for including sustainability in the different degrees, as can be seen from the high standard deviations shown in Figure 1(a).

Although Spanish universities have taken steps to integrate sustainability into curricula in recent years, there is still a long way to go (Tilbury, 2011; Segalàs et al., 2012). The results shown in figures 1(a) and (b) demonstrate the need to develop networks and joint projects between universities that enable convergence towards appropriate strategies that minimize the type deviations shown.

\subsection{Presence of sustainability competencies in the curricula}

The data shown in Figures 2(a), 2(b) and 2(c) yield the answers to the second block of the research questions: To what extent are sustainability competencies present in the curricula of each Degree? Is there a homogeneous treatment in the development of sustainability competencies between the different degrees? And between the different universities? Do significant differences exist between education and engineering degrees?

Figure 2(a) shows a comparison of the average presence of each of the four sustainability competencies ( $\mathrm{C} 1$ to $\mathrm{C} 4$ ) in the ten degrees analyzed. In the abscissa axis, the four education degrees (on the left) and the six engineering degrees (in the center) are identified in two groups. The group of bars on the right shows the average presence of each competency for all the analyzed curricula, classified by area of knowledge, and the weighted average of the 26 curricula. 

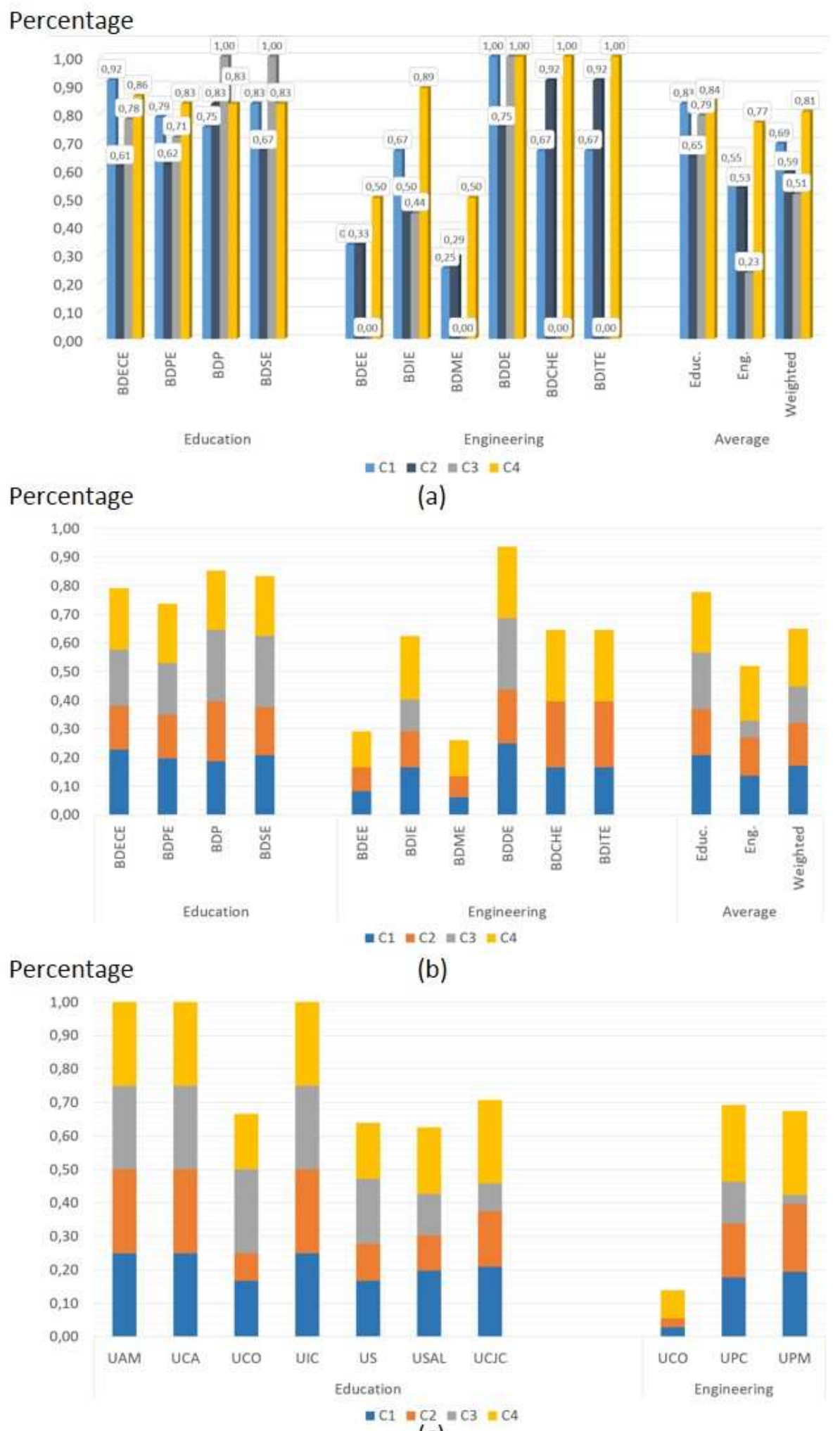

(c)

Fig 2 (a) Average percentage of presence of the sustainability competencies of the CRUE classified by degrees, area of knowledge, and weighted average. (b) Contribution of each of the four competencies to sustainability presence classified by degrees, area of knowledge and weighted average. (c) Contribution of each of the four competencies to sustainability presence, classified by universities in each area of knowledge

Analysis of the data presented in Figure 2(a) suggests that: 
- The four education degrees develop the four sustainability competencies (C1 to $\mathrm{C} 4)$ to a greater or lesser extent. However, four of the six engineering degrees analyzed (BDEE, BDME, BDCHE, BDITE) do not develop ( $0 \%$ ) competency C3-Participation in community processes.

- Education degrees develop the four sustainability competencies more homogeneously than engineering degrees. In addition, generally speaking, sustainability competencies are less developed in engineering degrees than in education degrees.

- On average, the competency with less presence in the field of Education is C2-Sustainable use of resources $(65 \%)$, while in the field of Engineering it is C3-Participation in community processes (23\%). In contrast, the competency C4-Application of ethical principles has the most presence in engineering degrees (77\%), while in education degrees the competencies C1-Critical contextualization of knowledge, C3-Participation in community processes, and C4 -Application of ethical principles have a similar presence (between $79 \%$ and $84 \%$ ).

- On average, the four sustainability competencies are present in both education degrees and engineering degrees, although their presence is greater in education degrees than in engineering degrees. This result seems logical if it is related to the block corresponding to the first research question, given that education degrees have on average more than twice as many subjects that develop sustainability as engineering degrees (Figure 1(a)).

Figure 2(b) contains the same information as Figure 2(a), but in a stacked and standardized manner. For each degree, competencies $\mathrm{C} 1$ through $\mathrm{C} 4$ are now shown in a single bar (stack) with four different shades. The purpose of Figure 2(b) is to show the degree of presence of sustainability in each degree. To this end, the methodology assumes that each of the $\mathrm{C} 1-\mathrm{C} 4$ competencies contributes $25 \%$ to sustainability. The highest bars correspond to the degrees having a greater presence of the four sustainability competencies, added with the same weighting.

As can be seen in the figure, the BDDE is the degree that shows the most presence of sustainability (94\%). This high level of presence is due to the fact that this degree is taught in a single university that shows a special sensitivity to the inclusion of sustainability competencies in the curriculum. The degree that shows less presence of sustainability is BDME, with just $26 \%$. This degree is taught in two universities, and clearly has not been designed with sustainability competencies in mind in any of them. When the data is analyzed by area of knowledge, education degrees have an average presence of $78 \%$, while engineering degrees barely reach $52 \%$, but with much more variability between them (BDME $\approx 26 \%$ vs BDDE $\approx 94 \%$ ).

Finally, Figure 2(c) shows the same information as Figure 2(b), but organized by universities in each area of knowledge. Figure 2(c) shows that the degrees within the scope of Education taught at the UAM, the UCA and the UIC have a 100\% sustainability presence. The three universities teach the BDECE and BDPE degrees, which implies that both degrees have a $100 \%$ presence of the 4 sustainability competencies. On the other hand, the sustainability presence in the remaining universities offering degrees in the field of Education (US, USAL, UCJC, UPC and UPM) is approximately $60 \%$.

With respect to engineering degrees, the three degrees taught at the UCO (BDEE, BDIE and BDME) barely reach $14 \%$ of sustainability presence on average, and none of them has a presence of the competency C3Participation in community processes. The UPC and UPM curricula have an average sustainability presence close to $60 \%$.

The comparative analysis of figures 2(b) and 2(c) suggests that a certain homogeneity exists in the development of sustainability within the same institution and area of knowledge, but not between institutions or between areas of knowledge. The case of the UCO is striking, since it seems to have a strategy for developing sustainability in education degrees, but not in engineering degrees.

The sustainability presence is on average more homogeneous in education degrees than in engineering degrees, which is compatible with education degrees having a greater motivation to include sustainability than engineering degrees, where motivation could depend more on a few especially motivated teachers.

Finally, it should be noted that the competency with the lowest presence in education degrees is C2Sustainable use of resources, while in engineering degrees it is C3-Participation in community processes. It is surprising that, according to the authors, the competency most present in engineering degrees is the C4-Application of ethical principles, rather than the C1-Critical contextualization of knowledge or the C2Sustainable use of resources, traditionally more entrenched in the engineering degrees. 


\subsection{Domain levels in which each of the sustainability competencies is developed}

In answer to the third block of research questions, Figure 3 is presented: What presence do the sustainability competencies have in each domain level of the taxonomy? Do significant differences exist between education and engineering degrees?

Figure 3 shows the average presence (axis y) of each of the three domain levels L1-Know, L2-Know how, L3-Demonstrate + Do of each competency C1 to C4 (axis x), classified according to the knowledge

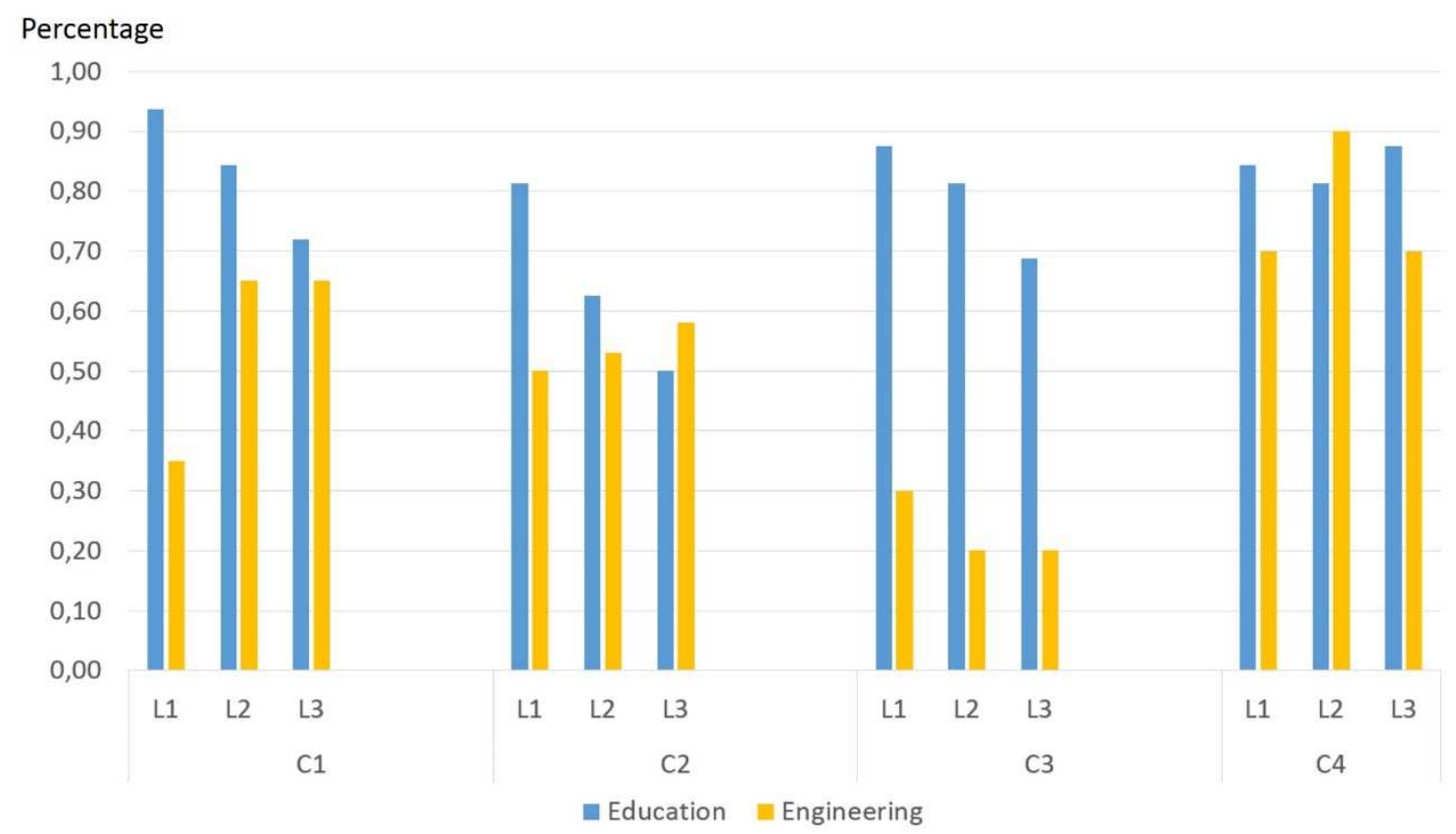

Fig 3 Average presence of sustainability competencies according to domain level and area of knowledge

The analysis in Figure 3 indicates that:

- In general, sustainability has a greater presence in education degrees than in engineering degrees in all domain levels. Only level L3 of the competency C2-Sustainable use of resources, and level L2 of the competency C4-Application of ethical principles, have a greater presence in engineering degrees.

- In the education degrees, the lowest domain levels (L1) are those that have, in general, a greater presence. In engineering degrees, on the other hand, domain level L1 has the least presence, with the exception of competency C3-Participation in community processes.

The foregoing result is not unexpected. Universities have traditionally been transmitters of knowledge (L1> L2, L3) and although there are currently models available for the integration of competencies, hardly any information exists about to put it into practice (Wihelm et al., 2019). On the other hand, the curriculum analysis of the universities that teach engineering studies show that the design of their curricula is oriented towards the development of more applicative tasks (Tejedor et al., 2018), causing the opposite effect (L1 $<\mathrm{L} 2, \mathrm{~L} 3)$.

\subsection{Correlation between the presence of sustainability competencies and the number of subjects that develop them}

Figure 4 provides answer to the fourth block of research questions: Is there a correlation between the number of subjects that develop sustainability in each curriculum and the presence of sustainability? If so, do significant differences exist in the correlation found between education and engineering degrees? 
Figure 4, which synthesizes much of the information contained in the previous figures, presents the correlation between the number of subjects in which it is stated that sustainability is developed (axis $\mathrm{x}$ ) and the sustainability presence (axis y), both for the Education and Engineering curricula. Education and Engineering curricula are labeled in two different tones to facilitate differentiation, and the trend line of the Education curricula is continuous, while the trend line of the Engineering curricula is discontinuous.

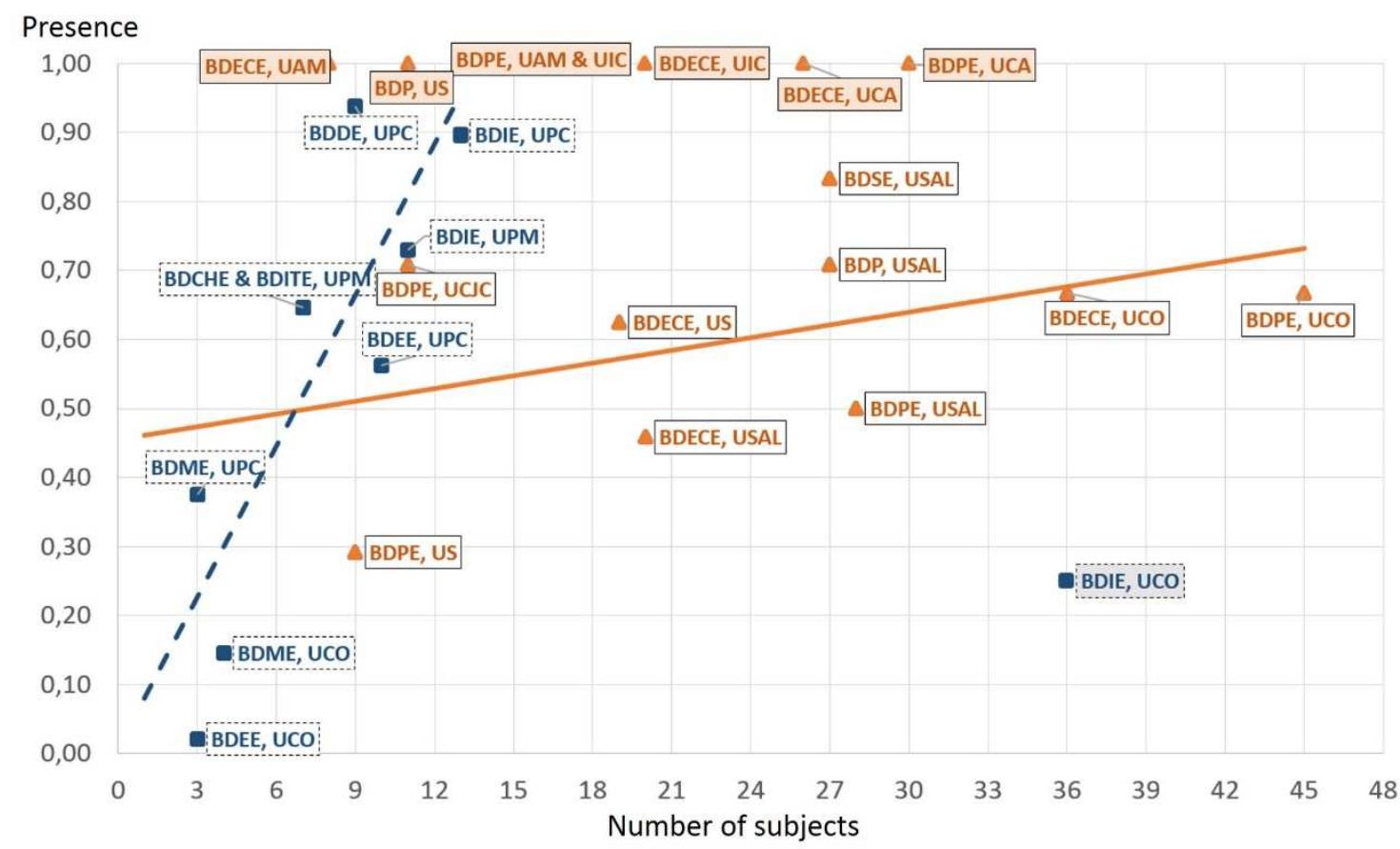

Fig 4 Correlation between sustainability presence and the number of subjects in which it is stated that sustainability is developed

Figure 4 shows different outliers, both in number and nature, according to the area of knowledge. It is considered that these outliers do not contribute to the trend lines (there is no trend line if these points are considered). The boxes containing the names of the outliers are filled in to help differentiate them from other curricula. Engineering curricula have a single outlier (BDIE, UCO), which corresponds to a curriculum with many subjects that state the development of sustainability (36) but with a sustainability presence of only $25 \%$. However, seven outliers are found in the area of education (BDECE, UAM; BDP, US; BDPE, UAM \& UIC; BDECE, UIC; BDECE, UCA; BDPE, UCA). These outliers correspond to curricula that declare a $100 \%$ sustainability presence with a very variable number of subjects, from 8 (BDECE, UAM) to 30 (BDPE, UCA). As can be seen, the nature of the outliers is different in engineering and education degrees.

The points corresponding to outliers in Education belong to curricula that could have a strategy for developing sustainability, since they show a $100 \%$ presence with a different number of subjects. On the other hand, the point corresponding to the engineering outlier corresponds to a curriculum that in all probability lacks such a strategy.

The remaining points form two trend lines, one for education degrees and one for engineering degrees. Each with its own slope, these lines suggest that sustainability presence increases with the number of subjects that develop it. It is difficult to draw conclusions from this fact, but these curricula probably do not have a defined strategy for developing sustainability either. If they did, they would be able to achieve a $100 \%$ sustainability presence with just a few subjects, as in the case of the BDECE of the UAM, which achieves $100 \%$ with only 8 subjects.

The foregoing results suggest the need to focus not so much on the "quantitative" aspect (number of subjects that develop sustainability), but rather on the "qualitative" aspect; that is, the design of an "appropriate strategy" that allows the integration of sustainability into the curriculum. An effective methodology to systematize this work is the use of Sustainability Maps (Sánchez-Carracedo et al., 2018-1; SánchezCarracedo et al., 2018-3). In a Sustainability Map, the important factor is not the number of subjects that 
develop sustainability (although a minimum number of subjects is required), but rather that the learning outcomes of the sustainability map are conveniently distributed among the subjects of the sustainability itinerary.

Finally, note that the slope of the Education and Engineering trend lines is different. The data indicate that engineering degrees generally require fewer subjects than education degrees in order to achieve the same sustainability presence. This may be due to the fact that education degrees develop the same sustainability map cells in many subjects, while other cells are not developed in any subject, which supports the previous hypothesis that they do not have a strategy for developing sustainability.

\subsection{Limitations of this research}

This work has some limitations, which are set out below:

- The study was conducted on a relatively small set of degrees (4 in the area of Education and 6 in Engineering), over 26 curricula (10 in Engineering and 16 in Education) that are taught in 9 different universities. The data cannot therefore be extrapolated to the rest of the education and engineering degrees in Spain. Nevertheless, they suffice to form an idea of how sustainability is being developed in some Higher Education curricula in Spain. In future work, it is necessary to study a larger set of degrees and curricula, including other knowledge fields, in order to complete the analysis conducted in this paper.

- The study was performed by analyzing the sustainability presence stated in the learning guides of the subjects of each curriculum. It may be that the teachers of the different subjects are not following the established learning guidelines to the letter. Future work should take this possibility into account, as well as the fact that not only the information contained in the learning guides should be considered, but also interviews with the teachers in order to verify the information. This requires some extensive and thorough work that should be carried out within each curriculum. The authors believe that Spanish Higher Education should have a joint strategy in order to enable the degrees to collect and share this information and thereby improve ESD.

- The last limitation of this work is the definition of "presence", which only considers that learning outcomes are present in the learning guides. In subsequent studies, it is necessary to go further and analyze not only whether or not a learning outcome is developed in a certain subject, but also how it is developed (with what methodologies); how it is evaluated (with what instruments), and how many hours students devote to it.

\section{Conclusions}

This paper analyzes the sustainability presence in the curricula of a set of Spanish Higher Education degrees in the fields of Education and Engineering. The results are analyzed on the basis of four parameters: (1) Number of subjects that develop sustainability in the curricula; (2) Presence of sustainability competencies in the curricula; (3) Domain levels in which each of the sustainability competencies is developed; and (4) Correlation between the presence of sustainability competencies and the number of subjects that develop them.

With respect to the first parameter -the number of subjects that develop sustainability in the different curricula-, the results indicate that there appears to be no clear "strategy" for implementing sustainability among the different Spanish universities (the average number of subjects dedicated to developing sustainability is very different, depending on the university). However, the data is compatible with the existence of such a strategy within each university (a small deviation is found in the number of subjects that develop sustainability in the different degrees taught by the same university). On the other hand, there appears to be no common strategy on the part of universities for including sustainability in the different degrees, as may be observed from the high standard deviations shown when the curricula of different universities corresponding to the same degree are analyzed.

With respect to the second parameter -the presence of sustainability competencies in the curricula-, the data suggests that a certain homogeneity exists in the development of sustainability within the same institution and area of knowledge, but not between different institutions or between areas of knowledge. Sustainability presence is more homogeneous in education degrees than in engineering degrees, which is compatible with education degrees being more motivated to include sustainability than engineering degrees. Finally, the competency C2-Sustainable use of resources has the lowest presence in education degrees, 
while in engineering degrees it is C3-Participation in community processes. It is surprising, on the other hand, that the competency most present in engineering degrees is C4-Application of ethical principles, instead of C1-Critical contextualization of knowledge or C2-Sustainable use of resources, traditionally more entrenched in engineering degrees.

As for the third parameter, education degrees have greater sustainability presence in the lower domain levels of the taxonomy, while in the engineering degrees the opposite is true, and the lower levels of the taxonomy have a lower presence of sustainability than the higher levels.

Finally, regarding the fourth parameter, there seems to be a correlation between the number of subjects that develop sustainability and the sustainability presence in the curriculum. However, engineering degrees appear to require fewer subjects than education degrees to achieve the same sustainability presence. In order to obtain trend lines, some curricula are regarded as outliers and have not been taken into account. In the case of education curricula, these outliers correspond to curricula that have a $100 \%$ sustainability presence regardless of the number of subjects that develop sustainability. These curricula could have a strategy for developing sustainability.

\section{Acknowledgments}

Authors wish to thank the rest of the EDINSOST team for their collaboration in this work, especially Miguel Antúnez, Antonio Gomera, Ibon Gutiérrez, Rafael Miñano, José Manuel Muñoz, Jorge Ruiz-Morales, and Rocío Valderrama-Hernández.

This work was supported by the Spanish Ministerio de Economía y Competitividad under Grant EDU201565574-R, and by Spanish Ministerio de Ciencia, Innovación y Universidades, the Spanish Agencia Estatal de Investigación (AEI) and the Fondo Europeo de Desarrollo Regional (FEDER) under grant number RTI2018-094982-B-I00, from study design to submission.

\section{References}

Alejandro-Cruz, J.S., Rio-Belver, R.M., Almanza-Arjona, Y.C., and Rodríguez-Andara, A. (2019), “Towards a Science Map on Sustainability in Higher Education”. Sustainability, Vol .11 No. 13, pp. 3521.

Berchin, I., Grando, V., Marcon, G., Corseuil, L. and Guerra, J. (2017), "Strategies to promote sustainability in higher education institutions: A case study of a federal institute of higher education in Brazil", International Journal of Sustainability in Higher Education, Vol. 18 No. 7, pp. 1018-1038.

Casarejos, F., Frota, M. and Gustavson, L. (2017), "Higher education institutions: a strategy towards sustainability". International Journal of Sustainability in Higher Education, Vol. 18 No. 7, pp. 995-1017.

Ceulemans, K. and De Prins, M. (2010), “Teacher's manual and method for SD integration in curricula”, Journal of Cleaner Production, Vol. 18 No. 7, pp. 645-651.

Chiong, K. S., Mohamad, Z. F. and Abdul Aziz, A. R. (2017), "Factors encouraging sustainability integration into institutions of higher education", International Journal of Environmental Science and Technology, Vol. 14 No. 4, pp. 911-922.

CRUE (2012), "Directrices para la sostenibilización curricular", available at: https://www.crue.org/Documentos\%20compartidos/Declaraciones/Directrices_Sosteniblidad_Crue2012.p df (accessed 31 ${ }^{\text {st }}$ October 2019).

Demssie, Y., Wesselink, R., Biemans, H.J.A. and Mulder, M. (2019), “Think outside the European box: Identifying sustainability competencies for a base of the pyramid context”, Journal of Cleaner Production, Vol. 221, pp. 828-838.

Fien, J. and Maclean, R. (2009), "Teacher Education for Sustainability. II. Two Teacher Education Projects from Asia and the Pacific", Journal of Science Education and Technology, Vol. 9 No. 1, pp. 3748. 
Giangrande, N., White, R. M., East, M., Jackson, R., Clarke, T., Saloff Coste, M. and Gil Penha-Lopes, A. (2019), "Competency Framework to Assess and Activate Education for Sustainable Development: Addressing the UN Sustainable Development Goals 4.7 Challenge", Sustainability, Vol. 11 No. 10, pp. 2832.

Hallinger, P. and Chatpinyakoop, C. (2019), “A Bibliometric Review of Research on Higher Education for Sustainable Development, 1998-2018”, Sustainability, Vol. 11 No. 8, pp. 2401.

Hill, L. M. and Wang, D. (2018), "Integrating sustainability learning outcomes into a university curriculum: A case study of institutional dynamics", International Journal of Sustainability in Higher Education, Vol. 19 No. 4, pp. 699-720.

IAU (2017), "Higher education paving the way to sustainable development: a global perspective. Report of the 2016 IAU Global Survey on Higher Education and Research for Sustainable Development", available at: https://iau-aiu.net/IMG/pdf/higher-education-paving-the-way-to-sd-iau-2017.pdf (accessed $31^{\text {st }}$ December 2019).

Jarchow, M. E., Formisano, P., Nordyke, S. and Sayre, M. (2018), "Measuring longitudinal student performance on student learning outcomes in sustainability education", International Journal of Sustainability in Higher Education, Vol. 19 No. 3, pp. 547-565.

Kates, R. W., Clark, W. C., Corell, R., Hall, J. M., Jaeger, C. C., Lowe, I., McCarthy, J. J., Schellnhuber, H. J., Bolin, B., Dickson, N. M., Faucheux, S., Gallopin, G. C., Grübler, A., Huntley, B., Jäger, J., Jodha, N. S., Kasperson, R. E., Mabogunje, A., Matson, P., Mooney, H., Moore III, B., O'Riordan, T. and Svedin, U. (2001), "Sustainability science”, Science, Vol. 292 No. 5517, pp. 641-642.

Koehn, P.H. and Uitto, J.I. (2014), "Evaluating sustainability education: lessons from international development experience", Higher Education, Vol. 14 No. 5, pp. 621-635.

Miller, R.E. (1990), “The assessment of clinical skills, competence, performance” Academic medicine, Vol. 65 No. 9 , pp. 63-77.

Mortensen, L.L. (2000), “Teacher Education for Sustainability. I. Global Change Education: The Scientific Foundation for Sustainability", Journal of Science Education and Technology, Vol. 9 No. 1, pp. 27-36.

Mulder, K.F., Segalàs, J. and Ferrer-Balas, D. (2012), "How to educate engineers for/in sustainable development: Ten years of discussion, remaining challenges", International Journal of Sustainability in Higher Education, Vol. 13 No. 3, pp. 211-218.

Poza-Vilches, F., López-Alcarria, A. and Mazuecos-Ciarra, N. (2019), “A Professional Competences' Diagnosis in Education for Sustainability: A Case Study from the Standpoint of the Education Guidance Service (EGS) in the Spanish Context", Sustainability, Vol. 11 No. 6, pp. 1568.

Ralph, M. and Stubbs, W. (2014), "Integrating environmental sustainability into universities", Higher Education, Vol. 67 No. 1, pp. 71-90.

Sánchez-Carracedo, F., Soler, A., Martín, C., López, D., Ageno, A., Cabré, J., Garcia, J., Aranda, J. and Gibert, K. (2018-1), "Competency Maps: an Effective Model to Integrate Professional Competencies Across a STEM Curriculum”, Journal of Science Education and Technology, Vol. 27 No. 5, pp. 448-468.

Sánchez-Carracedo, F., Climent, J., Corbalán, J., Fonseca i Casas, P., Garcia, J., Herrero, J.

R., Rodríguez, H. and Sancho, M. R. (2018-2), “A proposal to Develop and Assess Professional Skills in Engineering Final Year Projects”, International Journal of Engineering Education, Vol. 34 No. 2, pp. 400-413.

Sánchez-Carracedo, F., Segalàs, J., Vidal, E., Martín, C., Climent, J., López, D. and Cabré, J. (2018-3), "Improving engineering educators' sustainability competencies by using competency maps: The EDINSOST project”, International Journal of Engineering Education, Vol. 34 No. 5, pp. 1527-1537. 
Sánchez-Carracedo, F., Ruiz-Morales, J., Valderrama-Hernández, R., Muñoz-Rodríguez, J.M. and Gomera, A. (2019-1), "Analysis of the presence of sustainability in Higher Education Degrees of the Spanish university system", Studies in Higher Education, available at:

https://doi.org/10.1080/03075079.2019.1630811. (accessed 31 ${ }^{\text {st }}$ October 2019).

Sánchez-Carracedo, F., Moreno-Pino, F.-M., Sureda, B., Antúnez, M. and Gütéerrez, I. (2019-2), “A Methodology to Analyze the Presence of Sustainability in Engineering Curricula. Case of Study: Ten Spanish Engineering Degree Curricula”, Sustainability, Vol. 11 No. 17, pp. 4553.

Segalàs, J., Mulder, K. F. and Ferrer-Balas, D. (2012), "What do EESD “experts" think sustainability is? Which pedagogy in suitable to learn it?", International Journal of Sustainability in Higher Education, Vol. 13 No. 3, pp. 293-304.

Segalàs, J., Sánchez-Carracedo, F., Hernández, A., Busquets, P., Tejedor, G. and Horta, R.-_(2018), "The EDINSOST Project. Training sustainability change agents in Spanish and Catalan Engineering Education", in Proceedings of the Engineering Education for Sustainable Development Conference EESD 2018 in New Jersey, 2018, Rowan University, pp. 109-116.

Shephard, K. and Furnari, M. (2013), "Exploring what university teachers think about education for sustainability", Studies in Higher Education, Vol. 38 No. 10, pp. 1577-1590.

Sinakou, E., Boeve-de Pauw, J., Goossens, M. and Van Petegem, P. (2018), "Academics in the field of Education for Sustainable Development: Their conceptions of sustainable development”, Journal of Cleaner Production, Vol. 184, pp. 321-332.

Sonetti, G., Brown, M. and Naboni, E. (2019), “About the Triggering of UN Sustainable Development Goals and Regenerative Sustainability in Higher Education”, Sustainability, Vol. 11 No. 1, pp. 254.

Stephens, J.C. and Graham, A. C. (2010), "Toward an empirical research agenda for sustainability in higher education: exploring the transition management framework", Journal of Cleaner Production, Vol. 18 No. 7, pp. 611-618.

Svanström, M., Palme, U., Knutson Wedel, M., Carlson, O., Nyström, T. and Edén, M. (2012), "Embedding of ESD in engineering education: Experiences from Chalmers University of Technology", International Journal of Sustainability in Higher Education, Vol. 3 No. 3, pp. 279-292.

Tassone, V.C., O’Mahony, C., McKenna, E., Eppink, H.J. and Wals, A.E.J. (2018), “(Re-)designing higher education curricula in times of systemic dysfunction: a responsible research and innovation perspective", Higher Education, available at: https://doi.org/10.1007/s10734-017-0211-4 (accessed 31 ${ }^{\text {st }}$ October 2019).

Tejedor, G.; Segalàs, J. and Rosas-Casals, M. (2018), “Transdisciplinarity in higher education for sustainability: How discourses are approached in engineering education", Journal of Cleaner Production, Vol. 175, pp. 29-37.

Tejedor G.; Segalàs J.; Barrón A.; Fernández-Morilla M.; Fuertes M. T.; Ruiz-Morales J.; Gutiérrez I.; García-González E.; Aramburuzabala P. and Hernández A. (2019), "Didactic Strategies to Promote Competencies in Sustainability", Sustainability, Vol. 11, pp. 2086.

Tilbury, D. (2011), "Higher education for sustainability: a global overview of commitment and progress" in GUNI (Ed.), Higher Education in the World 4. Higher Education's Commitment to Sustainability: From Understanding to Action, Palgrave MacMillan, Barcelona, pp. 18-28.

UN (2015), "La agenda 2030 para el desarrollo sostenible. Resource document. United Nations General Assembly”, available at: https://undocs.org/en/A/RES/70/1 (accessed 31 $1^{\text {st }}$ October 2019).

UNESCO (2017-1), “Guidelines on Sustainability Science in Research and Education”, available at: https://unesdoc.unesco.org/ark:/48223/pf0000260600 (accessed 31 ${ }^{\text {st }}$ October 2019). 
UNESCO (2017-2), "Education for Sustainable Development Goals. Learning Objectives", available at: http://unesdoc.unesco.org/images/0024/002474/247444e.pdf (accessed 31 ${ }^{\text {st }}$ October 2019).

Wieck, A., Withycombe, L. and Redman, C.L. (2011), "Key competencies in sustainability: a reference framework for academic program development”, Sustainability Science, Vol. 6 No. 2, pp. 203-218.

Wiek, A., Bernstein, M., Foley, R., Cohen, M., Forrest, N., Kuzdas, C., Kay, B. and Withycombe Keeler, L. (2015), "Operationalising competencies in higher education for sustainable development", in Barth, M., Michelsen, G., Rieckmann, M. and Thomas, I. (Ed.), Routledge Handbook of Higher Education for Sustainable Development, Taylor \& Francis Group, London, pp. 241-260.

Wilhelm, S., Förster, R. and Zimmermann, A. B. (2019), "Implementing Competence Orientation: Towards Constructively Aligned Education for Sustainable Development in University-Level Teaching-AndLearning", Sustainability, Vol. 11 No. 7, pp. 1891.

\section{Authors}

Fermín Sánchez-Carracedo received his Ph.D. in computer science in 1996 from the UPC-BarcelonaTech. His fields of study include computer architecture, innovation in education and education for sustainability. Since 1987, he has been lecturing at the UPC-BarcelonaTech Department of Computer Architecture. He has more than 150 publications related to his research topics. Dr. Sánchez's awards include an Honorable Mention in the 1st European award for best practices for the integration of Sustainable Human Development into technology and engineering education (2013), the 2017 AENUI award for teaching quality and innovation, and the UPC 2019 award for social commitment in cooperation modality.

Barbara Sureda. Bachelor Degree in Industrial Engineering since 1987, Master Degree in Industrial Organization Engineering since 2000, and PhD in Industrial Engineering since 2007. Since 1988 she has been lecturing at the UPC in the Department of Graphic Expression in Engineering at UPC-BarcelonaTech. Her research areas are education for sustainability and climate change. She has been teaching coordinator at the UNESCO Chair of Sustainability at UPC-BarcelonaTech (2003-2010). She is currently coordinator of the Sustainability, Technology and Humanism research group of the UPC-BarcelonaTech.

Francisco Manuel Moreno-Pino. Bachelor Degree in Mathematical Sciences, specialized in Pure Mathematics since 1994, and Master Degree in Environmental Education since 2013. Full Professor in comprehensive school between 1994 and 2011. Currently he is a teacher at the University of Cádiz in the area of Mathematics Didactics, and teacher-tutor in the Cadiz' Associated Center of the UNED, in the Department of Industrial Technology Engineering. PhD candidate at the University of Malaga in Sciences Didactics and Environmental Education. His areas of research are mathematical modeling, mental models (APOE) and education for sustainability. 